\title{
A functional regression model for predicting optical depth and estimating attenuation coefficients in sea-ice covers near Resolute Passage, Canada
}

\author{
Shaun McDONALD, ${ }^{1}$ Theodoro KOULIS,${ }^{1}$ Jens EHN, ${ }^{2}$ Karley CAMPBELL, ${ }^{2}$ \\ Michel GOSSELIN, ${ }^{3}$ C.J. MUNDY ${ }^{2}$ \\ ${ }^{1}$ Department of Statistics, University of Manitoba, Winnipeg, Canada \\ ${ }^{2}$ Centre for Earth Observation Science, Clayton H. Riddell Faculty of Environment, Earth, and Resources, \\ University of Manitoba, Winnipeg, Canada \\ E-mail: cj.mundy@umanitoba.ca \\ ${ }^{3}$ Institut des Sciences de la Mer de Rimouski, Université du Québec à Rimouski, Rimouski, Québec, Canada
}

\begin{abstract}
The spectral dependence of natural light transmittance on ice algae concentration and snow depth in Arctic sea ice provides the potential to study the changing bottom-ice ecosystem using optical relationships. In this paper, we consider the use of functional data analysis techniques to describe such relationships. Specifically, we created a functional regression model describing spectral optical depth as a function of chlorophyll a concentration, snow depth and ice thickness. Measurements of the aforementioned covariates and surface and transmitted spectral irradiance were collected on landfast first-year sea ice in the High Arctic near Resolute Passage, Canada, during the spring of 2011 and used as model input. The derived model explains $75-84.5 \%$ of the variation in the observed spectral optical depth curves. No prior assumptions of snow/sea-ice optical properties are required in the application of this technique, as the model estimates the attenuation coefficients of each covariate using only the measurements mentioned above. The quality and simplicity of the model highlight the potential of functional data analysis to study the Arctic marine ecosystem.
\end{abstract}

KEYWORDS: sea ice, sea-ice ecology, snow

\section{INTRODUCTION}

Ice algae are an integral component of the Arctic icecovered marine ecosystem, where they provide an important initial food source for early spring grazers (e.g. Bradstreet and Cross, 1982; Horner and others, 1992; Leu and others, 2011). In recent decades, the Arctic marine environment has experienced numerous changes, including earlier melt onset (Markus and others, 2009), shrinking and thinning of multiyear sea ice (MYI) and a transition from MYI to predominantly first-year sea-ice (FYI) cover (Stroeve and others, 2012). These changes in algal habitat will influence ice algae abundance and productivity. For example, an earlier melt onset can shorten the ice algal bloom period (Campbell and others, 2014), whereas a change from multi-year to firstyear ice cover could favour higher ice algal production (Arrigo and others, 2010). However, we lack a sufficiently detailed understanding of the ice-covered ecosystem to quantify its actual response to the changing environment with any certainty. In particular, there is a deficit of spatial and temporal observations of ice algae and their environment across the Arctic (Arrigo and others, 2010). This paucity of data is partially due to logistic and methodological challenges (Nicolaus and others, 2012), as well as the destructive nature of most conventional ice algae sampling methods (Mundy and others, 2007).

Multiple studies have demonstrated a significant influence of ice algal biomass on the spectral distribution of light underneath ice covers (Maykut and Grenfell, 1975; Arrigo and others, 1991; Legendre and Gosselin, 1991; Perovich and others, 1993; Mundy and others, 2007; Fritsen and others, 2011). Absorption by algal pigments decreases the transmitted light, while acting to shift and narrow its spectral distribution from a broad peak centred at $\sim 460 \mathrm{~nm}$ under an ice cover with little algal biomass to a sharp peak centred at $\sim 570 \mathrm{~nm}$ under high ice algal concentrations (Mundy and others, 2007). In turn, this modification of transmitted light is likely to feed back and affect ice algal growth (Horner and Schrader, 1982; Grossi and others, 1987; Palmisano and others, 1987). Comprehensive knowledge of the ice cover's optical characterization is therefore essential to improve our understanding of the Arctic marine ecosystem, especially considering the expected impact of observed sea-ice changes on light transmission (Nicolaus and others, 2012).

Numerous efforts have been made to quantitatively describe the optical properties of ice covers. Many of these make use of radiative transfer models (e.g. Fritsen and others, 1998; Hamre and others, 2004; Perovich, 2005). While these models may be used effectively for purposes such as analysing spatio-temporally varying ice covers (Perovich, 1990) and estimating algae's effect on transmittance (Grenfell, 1991), they are limited by their requirement of a priori knowledge of an ice cover's qualitative characteristics. Recently, Nicolaus and others (2012) produced an Arctic-wide map of light distribution under summer sea ice, using a combination of satellite data and measurements from a remotely operated vehicle (ROV). Their approach allowed for large-scale estimations of light transmission through different types of ice and surface covers without a heavy dependence on assumptions and parameterizations, and was used to make predictions about the changing nature of the Arctic light environment. However, it could not be used to describe the ice cover's 
optical properties on the microscale, nor did it account for the spectral distribution of transmitted light. Other attempts to characterize ice covers have involved direct calculation of spectral attenuation coefficients. For instance, Perovich and others (1993) calculated a biomass-specific diffuse attenuation coefficient for algae by comparing transmitted irradiance beneath an ice cover before and after removing the bottom algal layer. Light and others (2008) derived spectral extinction coefficients for ice from irradiance profiles using a finite-difference formula. These direct methods allow more flexibility than radiative transfer models, but require a range of additional measurements. For instance, in the work of Light and others (2008) irradiance profiles had to be taken every $0.10 \mathrm{~m}$ within boreholes through the ice.

In this paper, we consider the spectral optical depth of Arctic sea ice. The spectral optical depth, denoted $\tau(\lambda)$, is a dimensionless, wavelength-dependent parameter that describes the attenuation of light at wavelength $\lambda$ as it passes through a medium and can be given by

$$
\tau(\lambda)=\ln \left(\frac{E_{\mathrm{d}, \text { top }}(\lambda)}{E_{\mathrm{d}, \text { bot }}(\lambda)}\right),
$$

where $E_{\mathrm{d} \text {, top }}(\lambda)$ and $E_{\mathrm{d} \text {, bot }}(\lambda)$ are the downwelling incident (on top of the snow-ice cover) and transmitted (below the bottom ice algal layer) spectral irradiances $\left(\mathrm{W} \mathrm{m}^{-2} \mathrm{~nm}^{-1}\right)$, respectively. For Arctic first-year snow-covered sea ice, the main components of light attenuation during the spring algal bloom are ice algal biomass, snow depth and sea-ice thickness (Perovich and others, 1998), although sediments and other absorbing constituents (e.g. soot) can also play an important attenuation role in specific areas of the Arctic (Light and others, 2008). Because of the strong dependence of attenuation on algae, snow and ice, a functional model can be used to describe optical depth at specific wavelengths as a function of these main attenuating components.

To create such a model, we used a statistical technique from the field of functional data analysis (FDA). FDA is the extension of traditional statistical methods, such as multiple linear regression and significance testing, to data that are curves over a domain, such as time or wavelength (Ramsay and Silverman, 2005). The main goal of FDA is to consider discrete measurements of these curves and to describe the underlying smooth functions from which the measurements originated. FDA techniques have been successfully applied in various fields, such as medicine (Sørensen and others, 2013), psychology (Vines and others, 2006) and biology (Müller and others, 2009).

Here we consider functional linear regression where the response variable is a smooth function and the covariates can be scalar or functional. We used discrete measurements of incident and transmitted irradiance to create smooth representations of optical depth as a function of wavelength. A functional linear regression model was then developed using optical depth as a functional response. Chlorophyll a (chla) concentration (a commonly used proxy for algal biomass), snow depth and ice thickness were used as scalar covariates. In this case, the regression coefficients were also smooth functions of wavelength.

The utility and uniqueness of our approach is a result of its entirely data-driven nature. Using only measurements of irradiance and the aforementioned covariates, our model estimated spectral attenuation coefficients for the entire ice cover without any prior assumptions about its composition.
Thus, it provides a relatively simple and computationally inexpensive way to analyse the optical properties of sea ice. FDA methods, such as those described here, may therefore facilitate improved understanding of the Arctic marine ecosystem.

\section{METHODS \\ Data collection}

Field data were collected on landfast FYI during the ArcticICE (Ice-Covered Ecosystem) 2011 campaign near Resolute Passage, Nunavut, Canada $\left(74^{\circ} 43.165^{\prime} \mathrm{N} ; 9^{\circ} 10.099^{\prime} \mathrm{W}\right)$ between 27 April and 24 June. A description of the dataset used in this paper is provided in detail elsewhere (Campbell and others, 2014). In short, every fourth day, three new and separate snow depth sites were selected for sampling to capture the range of snow depths in the region, which included high $(>0.18 \mathrm{~m})$, medium $(0.1-0.18 \mathrm{~m})$ and low $(<0.1 \mathrm{~m})$ snow sites. Sample sites were selected with snowdrifts that had relatively consistent depths over at least a $2 \mathrm{~m}$ diameter area. As conditions progressed into melt, the high and low sites transitioned into white ice and melt-pondcovered sea ice, respectively. During the morning and before the sites were disturbed, measurements of incident and transmitted spectral downwelling irradiance were made using a dual-head visible near-infrared spectrometer (Field Spec Pro, Analytical Spectral Devices Inc.) with a cosine receptor $\left(180^{\circ}\right.$ field of view) that measured spectral irradiance in $\mathrm{W} \mathrm{m}^{-2} \mathrm{~nm}^{-1}$ over wavelengths $350-1050 \mathrm{~nm}$ at a $1.4 \mathrm{~nm}$ bandwidth. Due to low transmittance that resulted in measurement noise towards shorter and longer wavelengths, we confined the spectral range used in this study to 400$700 \mathrm{~nm}$, i.e. the range of photosynthetically active radiation (PAR). At each measurement site, five transmitted irradiance spectra were recorded, then averaged.

Immediately following transmitted irradiance measurements, spread within the $2 \mathrm{~m}$ diameter area selected for site sampling, five snow depths were measured, three to five ice cores were extracted using a Kovacs Mark II corer $(0.09$ m diameter) and ice thickness was determined in each core hole. The number of cores collected depended on the amount of material required for analysis, visually determined in the field. Figure $1 \mathrm{~b}$ and $\mathrm{c}$ show the range of siteaveraged snow depths and ice thicknesses used in our analyses. The bottom $0.03 \mathrm{~m}$ (which accounted for a seasonally averaged $95 \%$ of the total chl a concentration of the entire ice core; Galindo and others, 2014) of the three to five site extracted cores were pooled into isothermal containers, and $0.2 \mu \mathrm{m}$ filtered sea water (FSW) was added at a dilution of approximately three parts FSW to one part ice melt, in order to minimize osmotic shock to the microbial community during melt (Garrison and Buck, 1986). Samples were then left to melt in the dark over $12-$ 24 hours. Once melted, subsamples and a daily FSW blank were filtered onto glass fibre $F$ grade (GF/F) $25 \mathrm{~mm}$ filters and then stored in $\mathrm{a}-80^{\circ} \mathrm{C}$ freezer for analyses of algal pigment composition and concentration using reverse-phase high-performance liquid chromatography (HPLC). With the exception of using a different instrument, the HPLC analysis procedures applied followed those described by Alou-Font and others (2013). Namely, an Agilent Technologies 1200 Series was used with an Agilent Quaternary pump (model $61311 \mathrm{~A}$ ) for gradient elution. Furthermore, pigments were 

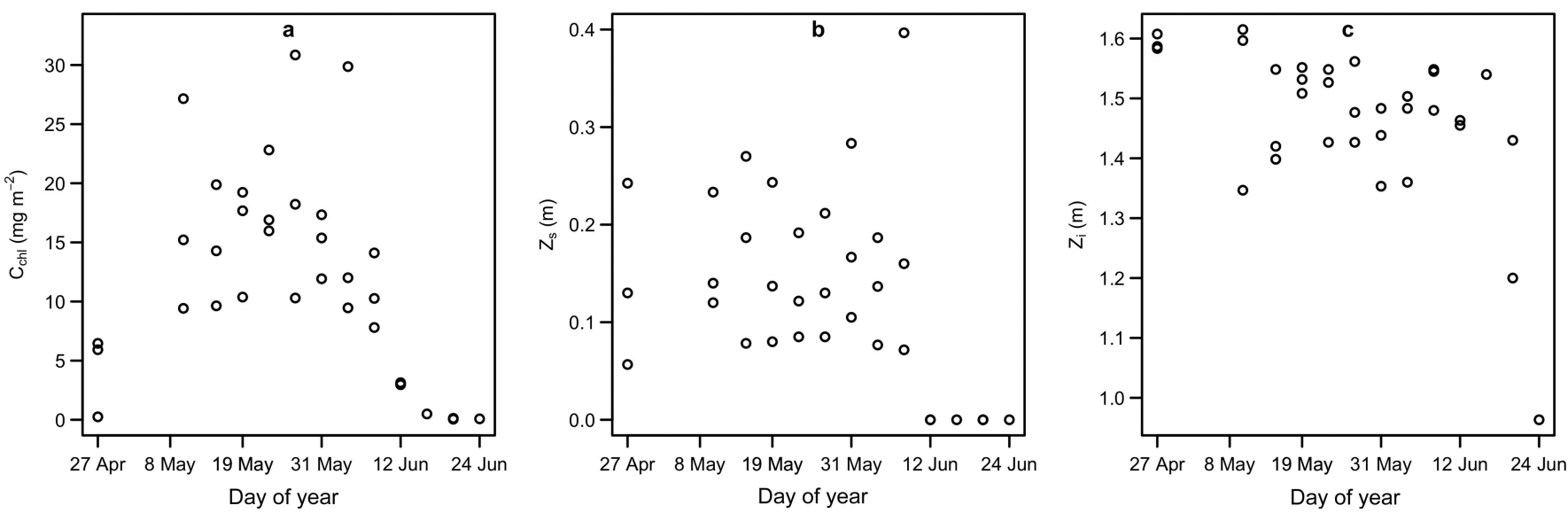

Fig. 1. Site-averaged time series plots of (a) areal concentration of Tchla, $C_{\text {chl }}$, (b) snow depth, $Z_{s}$, and (c) thickness of sea ice, $Z_{i}$. $Z_{s}$ was equal to zero during the melt, when melt ponds and drained ice replaced snow as the top of the ice cover.

detected using an Agilent diode-array absorbance detector (model 61315D; 400-700 nm) and an Agilent fluorescence detector (model 61321A) to confirm the presence of chlorophyll-related compounds. In this study, total chla (Tchl a) concentration was defined as the pigment concentration sum of chl a, its epimers and allomers, chlorophyllide a and methylchlorophyllide a, and was used as a proxy for photosynthetic biomass.

\section{Statistical analysis}

Functional data analysis considers functional data arising from discrete observations of smooth functions; in this sense, the fundamental unit of observation for FDA is a curve. The goals of FDA are similar to those of more traditional statistical analyses, and include data representation and visualization, as well as the study of important sources of patterns and variation within the data. Functional versions of analysis of variance, multiple regression analysis and principal components analysis are readily available. A recurring theme in FDA is the use of information in the derivatives of functions. Several FDA methods have readily been implemented in state-of-the-art software (e.g. MATLAB ${ }^{\circledR}$ and R (Ramsay and Silverman, 2005; Ramsay, 2006; Ramsay and others, 2009; R Core Team, 2013)).

In the study of environmental processes, functional data are often produced as collections of discrete measurements. The measurements within each collection usually possess a high-resolution and a low-noise component and are sometimes interpolated with the aim of characterizing an underlying smooth function that best describes the data. In general, the underlying function is defined over a continuous domain. For longitudinal data, such as temperature or precipitation time series, the domain is time, and in the case of spectral irradiance the domain is wavelength. If the measurements are made without error, then the function can be recovered via interpolation. However, observational error and natural variability in environmental (i.e. snow, ice and ice algal) properties are often present, so the recovery of the underlying function is improved via smoothing techniques.

\section{Smoothing $\tau(\lambda)$}

In our study, we considered discrete measurements of incident and transmitted irradiance at several hundred wavelengths to obtain optical depth measurements of the form $y_{l 1}, y_{l 2}, \ldots, y_{I n}$, where $/$ is used to index snow depth site and $n$ is the number of wavelength measurements. For each site, I, the measurement $y_{l j}$ equates to an optical depth $\tau_{l}\left(\lambda_{j}\right)$ at the specific wavelength $\lambda_{j}$, for $j=1,2, \ldots, n$. Each optical depth curve, $\tau_{l}(\lambda)$, was reconstructed as a regression spline (Ramsay and Silverman, 2005), and in our application we considered $B$-splines of order 6 with knots placed every $2 \mathrm{~nm}$. To reduce observational error, we used the roughness penalty approach to construct the regression splines for each optical depth curve. This method imposed additional smoothness by restricting the size of the third-order derivatives of the curves. Smoothing was controlled through a smoothing parameter, which was chosen to minimize the generalized cross-validation criterion (Craven and Wahba, 1978). In our application, the third derivative of $\tau_{l}(\lambda)$ was penalized using a smoothing parameter of $10^{-0.75}$.

\section{Functional regression model for $\tau(\lambda)$}

The Arctic ice cover was treated as a vertical arrangement of three distinct layers: a top layer of seasonally varying composition, a middle layer of sea ice with thickness $Z_{i}(\mathrm{~m})$ and a bottom layer of algal biomass. For this bottom layer, $C_{\mathrm{chl}}$ was the areal concentration of Tchl a $\left(\mathrm{mg} \mathrm{m}^{-2}\right)$.

The top layer consisted of snow of depth $Z_{\mathrm{s}}(\mathrm{m})$ from 27 April to 6 June 2011. During this interval, shortwave albedo remained approximately constant at 0.84 (Galindo and others, 2014). After 6 June, melt progressed, followed by a sharp decline in shortwave albedo, resulting in a surface ice cover of drained white ice interspersed with melt ponds (Campbell and others, 2014; Landy and others, 2014). The observed depths of the drained ice layer above the water table (referred to as white ice; Maykut and Grenfell, 1975) and melt ponds were small, having maxima of 0.10 and $0.06 \mathrm{~m}$, respectively. The drop in albedo associated with surface covers of these types had a significant influence on optical depth. Measurements made during the melt were few in number relative to the entire dataset, but critical for capturing the full range of $C_{\text {chl }}$ (i.e. $C_{\text {chl }}$ approached $0 \mathrm{mg} \mathrm{m}^{-2}$ during the melt progression; Campbell and others, 2014). Because the top layer of the ice cover was devoid of actual snow during this time, we set $Z_{s}$ to zero for these observations (Fig. 1 shows site-averaged time series plots of $C_{\mathrm{chl}}, Z_{\mathrm{s}}$ and $Z_{\mathrm{i}}$ ).

Functional regression was used to link spectral optical depth to the scalar covariates, $C_{\mathrm{chl}}, Z_{\mathrm{s}}$ and $Z_{\mathrm{i}}$. This technique 

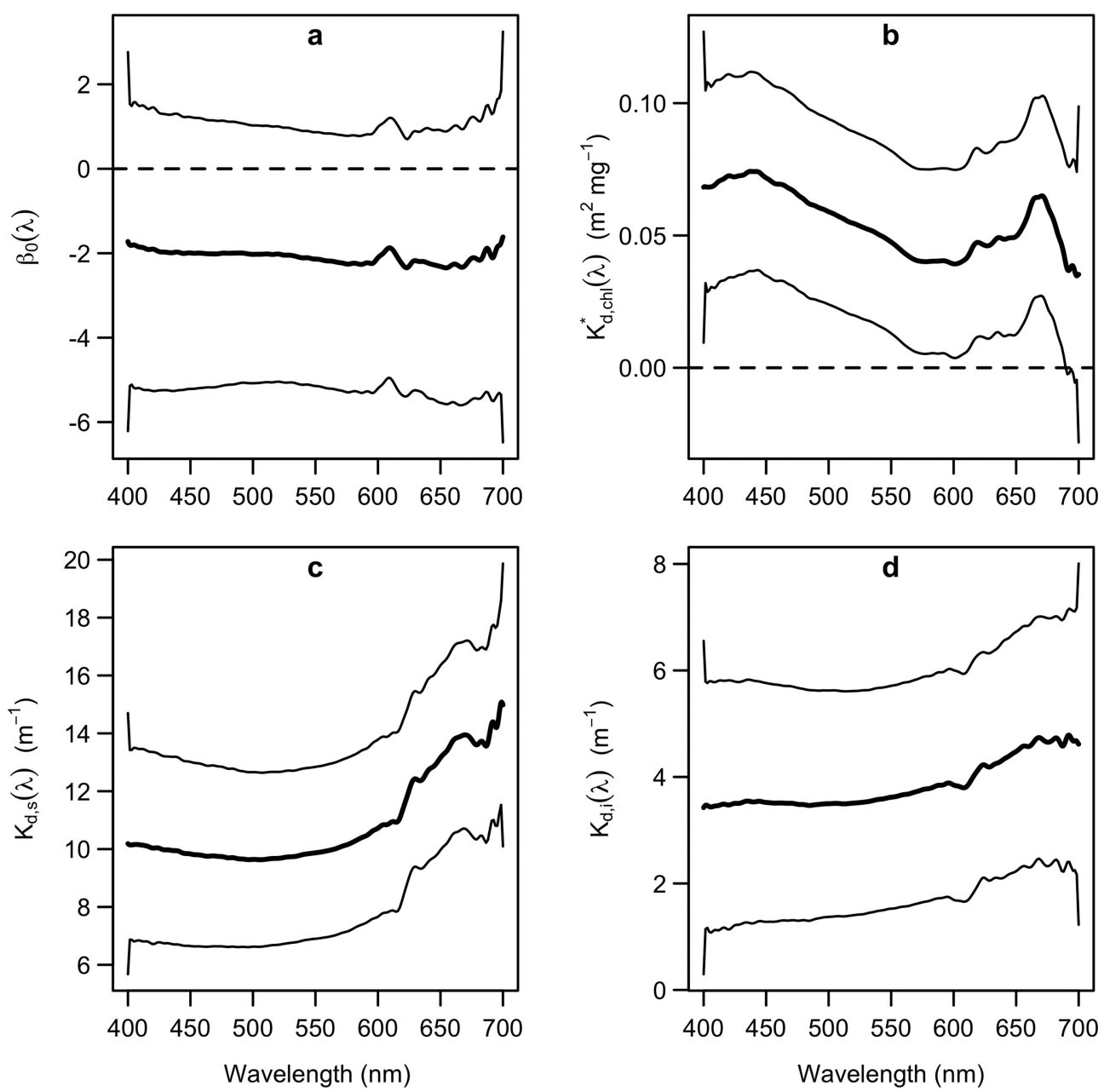

Fig. 2. Estimated coefficient functions (thick solid curves) and associated $95 \%$ confidence intervals (thin solid curves) of the functional regression model (Eqn (2)): (a) functional intercept; (b) Tchl a-specific diffuse attenuation coefficient; (c) attenuation coefficient of snow; and (d) attenuation coefficient of ice.

is an extension of traditional regression to the case where either the dependent or the independent variables are functional. In our setting, the functional response was $\tau(\lambda)$ with $\lambda$ restricted to PAR, as mentioned above. The functional linear regression model we used for $\tau(\lambda)$ was of the form

$$
\begin{aligned}
\tau(\lambda)= & \beta_{0}(\lambda)+K_{\mathrm{d}, \mathrm{chl}}^{*}(\lambda) \cdot C_{\mathrm{chl}}+K_{\mathrm{d}, \mathrm{s}}(\lambda) \cdot Z_{\mathrm{s}} \\
& +K_{\mathrm{d}, \mathrm{i}}(\lambda) \cdot Z_{\mathrm{i}}+\epsilon(\lambda),
\end{aligned}
$$

where the dimensionless function, $\epsilon(\lambda)$, represents a mean zero stochastic error process. The functional regression coefficients are interpreted as attenuation coefficients. Specifically, $K_{\mathrm{d} \text {, chl }}^{*}(\lambda)$ is the Tchla-specific diffuse attenuation coefficient $\left(\mathrm{m}^{2} \mathrm{mg}^{-1}\right)$, and $K_{\mathrm{d}, \mathrm{s}}(\lambda)$ and $K_{\mathrm{d}, \mathrm{i}}(\lambda)$ are the spectral diffuse attenuation coefficients $\left(\mathrm{m}^{-1}\right)$ of snow and ice, respectively. The intercept function, $\beta_{0}(\lambda)$ (dimensionless), represents effects on optical depth not accounted for by the covariates, including reflection and scattering due to impurities in the ice. A functional regression coefficient with a value of 0 at a given wavelength implies that its corresponding covariate has no effect on $\tau(\lambda)$ at that wavelength. Smith and others (1988) used a non-functional equation of the same form to model photon fluence rate ( $\mu$ mol quanta $\mathrm{m}^{-2} \mathrm{~s}^{-1}$ ).

The regression coefficients, $K_{\mathrm{d}, \mathrm{s}}(\lambda), K_{\mathrm{d}, \mathrm{i}}(\lambda)$ and $K_{\mathrm{d}, \mathrm{chl}}^{*}(\lambda)$, and intercept term, $\beta_{0}(\lambda)$, were expressed using order 6
$B$-spline bases with knots placed every $4 \mathrm{~nm}$. Fitting was accomplished by minimizing the regularized integrated residual sum of squares (Ramsay and Silverman, 2005). A smoothing parameter of $10^{-2}$ was applied to the third derivatives of the coefficient functions, chosen to minimize the cross-validated integrated squared error (Ramsay and others, 2009). All analyses were performed using the ' $R$ environment for statistical computing'. Functional regression fitting and statistical analyses (confidence intervals for regression coefficients, goodness-of-fit and significance testing) were conducted with the help of the fda package (Ramsay and others, 2012). The R code and coefficient estimates used are available upon request from the authors.

\section{RESULTS AND DISCUSSION}

\section{Attenuation coefficients}

The confidence intervals of $K_{\mathrm{d}, \text { chl }}^{*}(\lambda), K_{\mathrm{d}, \mathrm{s}}(\lambda)$ and $K_{\mathrm{d}, \mathrm{i}}(\lambda)$ (Fig. 2b-d) did not include 0 at any wavelength, except for $K_{\mathrm{d}, \mathrm{chl}}^{*}(\lambda)$ over the wavelength range $690-700 \mathrm{~nm}$. Hence, there is evidence to suggest that Tchl a, snow depth and ice thickness affect optical depth over almost all of the PAR range. Contrastingly, the zero value was included in the confidence interval of the intercept term, $\beta_{0}(\lambda)$, at every wavelength (Fig. 2a), indicating that the covariates accounted for most of the variation in the optical depth 


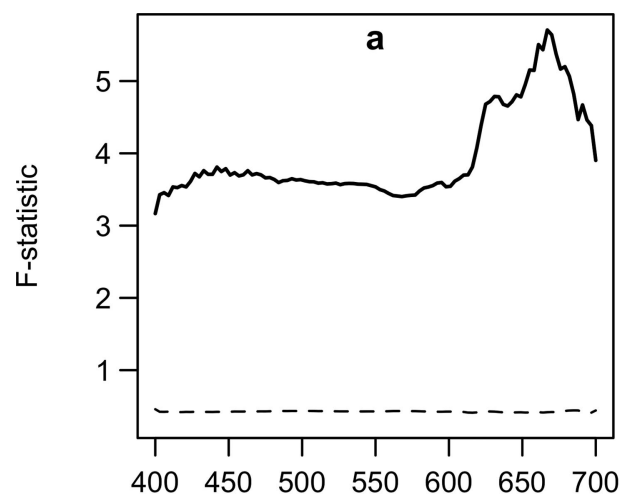

Wavelength (nm)

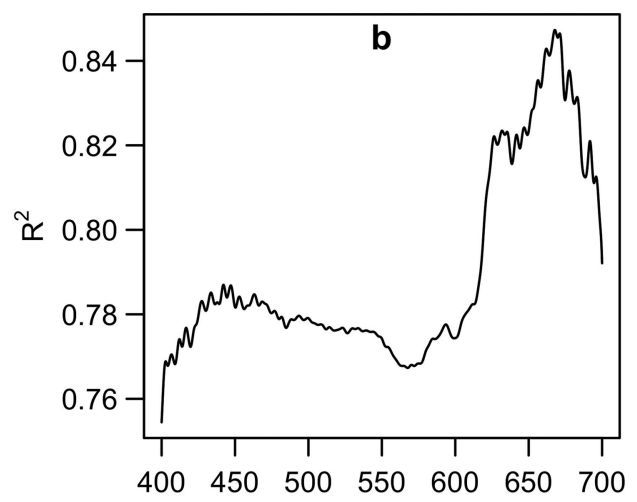

Wavelength $(\mathrm{nm})$

Fig. 3. (a) Functional F-statistic (solid curve) for a predictive relationship between Tchl a concentration, snow depth, ice thickness and spectral optical depth at each wavelength in the PAR range. The $1 \%$ critical value of the null distribution (dashed line) is displayed at the bottom. (b) The functional coefficient of variation, $R^{2}$, for the model as a function of wavelength.

measurements. For each layer of the ice matrix, PARintegrated attenuation coefficients were obtained by averaging the functional coefficients over PAR wavelengths, weighting by the irradiance above and below the layer in question (following Ehn and Mundy, 2013). The observed ranges of snow depth and ice thickness did not substantially affect the values of these coefficients.

The shapes of $K_{\mathrm{d} \text {, chl }}^{*}(\lambda)$ and $K_{\mathrm{d}, \mathrm{s}}(\lambda)$ were in agreement with published results: $K_{\mathrm{d} \text {, chl }}^{*}(\lambda)$ had peaks at $\sim 440$ and $670 \mathrm{~nm}$ (Perovich and others, 1993; Mundy and others, $2007)$ and $K_{\mathrm{d}, \mathrm{s}}(\lambda)$ had a characteristic J shape (Grenfell and Maykut, 1977). Although the shape of $K_{\mathrm{d}, \mathrm{chl}}^{*}(\lambda)$ was in agreement with the Tchla-specific absorption spectrum, it was higher by an offset of $\sim 0.05 \mathrm{~m}^{2} \mathrm{mg}^{-1}$ relative to that of Ehn and Mundy (2013). Thus, it is likely that the total attenuation per unit of Tchla includes a scattering effect associated with algae embedded within the ice matrix (Ehn and others, 2008a; Ehn and Mundy, 2013). The PARintegrated Tchla-specific attenuation coefficient, $K_{\mathrm{d} \text {, chl }}^{*}(\mathrm{PAR})$, was $0.06 \mathrm{~m}^{2} \mathrm{mg}^{-1}$, substantially larger than the $0.035 \mathrm{~m}^{2} \mathrm{mg}^{-1}$ estimated by Smith and others (1988). It is noteworthy that Smith and others (1988) observed an increase in their $K_{\mathrm{d} \text {, chl }}^{*}(\mathrm{PAR})$ estimate when an outlying Tchl a measurement of $110 \mathrm{mg} \mathrm{m}^{-2}$ was removed from their regression. This led them to suggest that $K_{\mathrm{d} \text {, chl }}^{*}(\mathrm{PAR})$ might decrease with increasing Tchla. Such a relationship would be consistent with the influence of an intercellular package effect on $K_{\mathrm{d} \text {, chl }}^{*}(\mathrm{PAR})$, i.e. less Tchla in the ice would increase the absorption efficiency per Tchla, due to less intercellular self-shading. We note that our maximum range of Tchla (30.85 $\mathrm{mg} \mathrm{m}^{-2}$ ) was approximately one-quarter that used in the regression of Smith and others (1988), in which the maximum Tchla value was $\sim 120 \mathrm{mg} \mathrm{m}^{-2}$. Therefore, such an intercellular package effect could help to explain our higher $K_{\mathrm{d} \text {, chl }}^{*}(\mathrm{PAR})$ estimate.

The magnitude of $K_{\mathrm{d}, \mathrm{s}}(\lambda)$ fell between the dry and melting snow coefficients summarized by Perovich (1990), and its PAR-integrated value was $11 \mathrm{~m}^{-1}$, which fell within the range of values observed at a nearby location and a similar time of year by Mundy and others (2005). Contrastingly, the magnitude of $K_{\mathrm{d}, \mathrm{i}}(\lambda)$ was slightly larger than the interior white ice and cold blue ice attenuation coefficients given by Perovich (1990), with a PAR-integrated value of $3.6 \mathrm{~m}^{-1}$. This difference could be in part attributed to the greater scattering associated with the surface granular and drained white ice layers, and the bottom skeletal ice layers of a first-year ice cover (Ehn and others, 2008b). Furthermore, $K_{\mathrm{d}, \mathrm{i}}(\lambda)$ deviated from an expected J shape (Grenfell and Maykut, 1977), with a small secondary peak in the wavelength range $\sim 440 \mathrm{~nm}$, close to the main absorption peak of Tchla. Therefore, the model appeared to attribute a small algal biomass influence on optical depth to sea ice. This slight effect could be attributed to variability in Tchl a concentration above the bottom 0.03 m layer, i.e. above the portion of ice where Tchl a measurements were derived.

We note that all of the coefficients had slight edge effects. For instance, $K_{\mathrm{d}, \mathrm{s}}(\lambda)$ experienced a local minimum at $\sim 690 \mathrm{~nm}$ (Fig. 2c). Much of this variation could be due to statistical noise. Nevertheless, the level of consistency that the regression coefficients exhibited with previously established results is promising, given the inherent uncertainty in their statistical estimation.

\section{Summary statistics}

The functional coefficient of variation, $R^{2}$, and $F$-statistic (Ramsay and Silverman, 2005) were used to assess model fit (Fig. 3). A permutation $F$-test was used to test the hypothesis that the covariates $C_{\mathrm{chl}}, Z_{\mathrm{s}}$ and $Z_{\mathrm{i}}$ had no effect on optical depth. The observed functional $F$-statistic was well above the $1 \%$ critical value (Fig. $3 \mathrm{a}$ ), leading to the conclusion that the model provided sufficient evidence that areal Tchl a concentration, snow depth and ice thickness had a statistically significant effect on optical depth over the PAR range. In addition, the functional $R^{2}$ statistic varied from $\sim 75 \%$ to $84.5 \%$ over the PAR range (Fig. $3 \mathrm{~b}$ ). Hence, at every value of $\lambda$, most of the variation in $\tau(\lambda)$ was explained by the model.

It is significant to note that the $R^{2}$ statistic had features in common with both $K_{\mathrm{d}, \mathrm{s}}(\lambda)$ and $K_{\mathrm{d}, \mathrm{chl}}^{*}(\lambda)$, including peaks around 440 and $670 \mathrm{~nm}$, a minimum at $\sim 575 \mathrm{~nm}$ and a general trend of decrease from 450 to $550 \mathrm{~nm}$ followed by a sharp increase from 575 to $670 \mathrm{~nm}$ (Fig. 2b and c). The shape of the $R^{2}$ curve therefore suggests that the ability of the model to explain variation in the optical depth data is directly related to the attenuation caused by the covariates included in the model. 

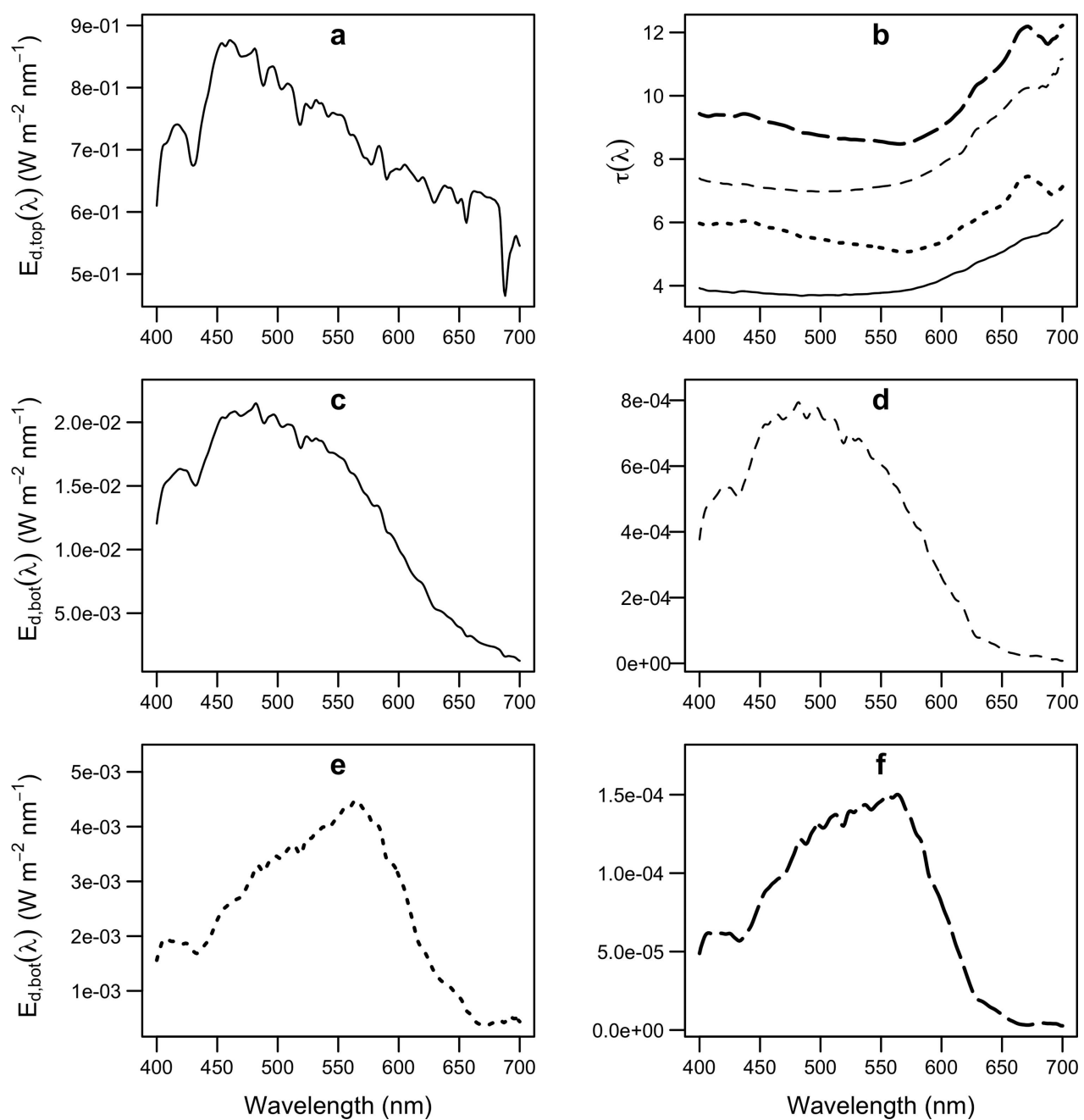

Fig. 4. (a) Spectral irradiance incident on an Arctic ice cover. (b) A sample of optical depth curves corresponding to low snow depth and low Tchl a (solid curve), high snow depth and low Tchl a (thin dashed curve), low snow depth and high Tchl a (dotted curve) and high snow depth and high Tchl a (thick dashed curve). (c-f) Transmitted irradiance spectra corresponding to the optical depth curves in (b).

\section{Prediction of optical depth and transmitted irradiance}

Using a measured incident irradiance spectrum from the original dataset, the estimated regression coefficients from our model and a variety of covariate values, we calculated several transmitted irradiance spectra according to

$$
\begin{aligned}
E_{\mathrm{d}, \text { bot }}(\lambda)= & E_{\mathrm{d}, \text { top }}(\lambda) \cdot \exp \left[-\left(\beta_{0}(\lambda)+K_{\mathrm{d}, \mathrm{chl}}^{*}(\lambda) \cdot C_{\mathrm{chl}}\right.\right. \\
& \left.\left.+K_{\mathrm{d}, \mathrm{s}}(\lambda) \cdot Z_{\mathrm{s}}+K_{\mathrm{d}, \mathrm{i}}(\lambda) \cdot Z_{\mathrm{i}}\right)\right]
\end{aligned}
$$

We compared low $(0.06 \mathrm{~m})$ and high $(0.4 \mathrm{~m})$ snow depths, $Z_{s}$, to low $\left(0.05 \mathrm{mg} \mathrm{m}^{-2}\right)$ and high $\left(30.0 \mathrm{mg} \mathrm{m}^{-2}\right)$ Tchla concentrations, $C_{\mathrm{chl}}$. These values approximately corresponded to the observed nonzero range of each covariate (Fig. 1). $Z_{i}$ was set to $1.47 \mathrm{~m}$, the mean value of ice thickness for our dataset. A schematic representation of these calculations is presented in Figure 4. Not surprisingly, transmitted irradiance spectra (Fig. 4c- $f$ ) were at least one order of magnitude smaller than the incident spectrum (Fig. 4a). Increasing snow depth caused an upward vertical shift in optical depth, whereas increasing Tchla concentration caused a similar vertical shift, as well as a change in the spectral shape (Fig. 4b). In particular, the optical depth curves corresponding to high Tchla concentrations exhibited similar peaks to those of $K^{*}{ }_{\text {, chl }}(\lambda)$, whereas those corresponding to low Tchl a concentrations had shapes that more closely resembled $K_{\mathrm{d}, \mathrm{s}}(\lambda)$. The effects of snow and Tchla on $\tau(\lambda)$ were reflected in the corresponding transmitted irradiance curves (Fig. 4c-f). Increasing snow depth caused the transmitted irradiance spectra to decrease in magnitude, while approximately maintaining their shape and peak structure (Fig. 4c-f). Increasing Tchl a concentration caused smaller changes in magnitude, but also changed the shapes of the spectra: low Tchl a spectra exhibited maxima in the mid-400s to early 500s, while high Tchl a spectra were low in the late 400s relative to their peaks in the late 500s (Fig. 4c-f). These results are consistent with the dominance of the attenuation properties of snow and Tchl a by scattering and absorption, respectively (Mundy and others, 2007).

\section{CONCLUSIONS}

Our functional linear regression model provided statistically significant evidence of the individual effects of ice algae biomass, snow and ice on optical depth, in addition to providing strong evidence of an overall predictive relationship. Furthermore, the model explained $75-84.5 \%$ of the variation in the values of the observed $\tau(\lambda)$ curves, and was used to predict transmitted irradiance. Although the inherent optical properties of the covariates were not explicitly accounted for in the model, their estimated effects on 
optical depth were largely consistent with expected results from previous work.

Unlike more comprehensive radiative transfer models (e.g. Perovich, 1990; Hamre and others, 2004; Ehn and others, 2008a,b), our model did not require any prior assumptions of the Arctic ice cover's optical properties. Using only a relatively small dataset, consisting of measurements of Tchl a concentration, snow depth, ice thickness and irradiance, we successfully estimated spectral attenuation coefficients for each defined layer of the ice cover. Although our model's treatment of the ice cover is not as detailed as those of the aforementioned radiative transfer models, its strong performance and agreement with previous results indicate that it provides a relatively simple way to independently estimate the effects of covariates on spectral optical depth and to verify the legitimacy of these effects. More generally, it shows that FDA can be used to model relationships, estimate quantities and validate previous results in the Arctic marine ecosystem in a straightforward and versatile way. The use of statistical methods also allows for rigorous scrutiny of results through significance testing and error analysis.

Future work will involve refinements to the model presented here, which was limited in its treatment of factors such as reflectance by the simplicity of the dataset. We will also attempt to use similar FDA techniques to predict chl a concentrations using transmitted spectral irradiance measurements. Using such techniques in conjunction with irradiance measurements made by ROVs across wide spatio-temporal regions (e.g. Nicolaus and Katlein, 2013) would facilitate large-scale, non-destructive estimation of algal biomass, a critically important contribution considering the destructiveness and difficulty associated with direct algal measurements (Mundy and others, 2007). Furthermore, we will explore the possibility of analysing changes in the Arctic ice cover's optical properties over time by applying our models to similar datasets taken from Resolute Passage in different years and comparing the estimated coefficients. These uses of functional data analysis provide the potential for crucial new insights into the changing Arctic ice cover and marine ecosystem.

\section{ACKNOWLEDGEMENTS}

This work was supported by funding from the Natural Sciences and Engineering Research Council of Canada, Canada Economic Development and Polar Continental Shelf Program of Natural Resources Canada. We thank Mélanie Simard and Joannie Charette for the HPLC pigment analysis. This is a contribution to the research programs of ArcticNet, Arctic Science Partnership (ASP) and the Canada Excellence Research Chair unit at the Centre for Earth Observation Science.

\section{REFERENCES}

Alou-Font E, Mundy C-J, Roy S, Gosselin M and Agusti S (2013) Snow cover affects ice algal pigment composition in the coastal Arctic Ocean during spring. Mar. Ecol. Progr. Ser., 474, 89-104 (doi: 10.3354/meps10107)

Arrigo KR, Sullivan CW and Kremer JN (1991) A bio-optical model of Antarctic sea ice. J. Geophys. Res., 96(C6), 10 581-10 592 (doi: 10.1029/91JC00455)

Arrigo KR, Mock T and Lizotte MP (2010) Primary producers and sea ice. In Thomas DN and Dieckmann GS eds. Sea ice. WileyBlackwell, Chichester
Bradstreet MSW and Cross WE (1982) Trophic relationships at High Arctic ice edges. Arctic, 35(1), 1-12 (doi: 10.14430/ arctic2303)

Campbell K, Mundy C-J, Barber DG and Gosselin M (2014) Remote estimates of ice algae biomass and their response to environmental conditions during spring melt. Arctic, 67(3), 375-387 (doi: 10.14430/arctic4409)

Craven P and Wahba G (1978) Smoothing noisy data with spline functions. Numer. Math., 31(4), 377-403 (doi: 10.1007/ BF01404567)

Ehn JK and Mundy CJ (2013) Assessment of light absorption within highly scattering bottom sea ice from under-ice light measurements: implications for Arctic ice algae primary production. Limnol. Oceanogr., 58(3), 893-902 (doi: 10.4319/lo.2013. 58.3.0893)

Ehn JK, Mundy CJ and Barber DG (2008a) Bio-optical and structural properties inferred from irradiance measurements within the bottommost layers in an Arctic landfast sea ice cover. J. Geophys. Res., 113(C3), C03S03 (doi: 10.1029/ 2007JC004194)

Ehn JK, Papakyriakou TN and Barber DG (2008b) Inference of optical properties from radiation profiles within melting landfast sea ice. J. Geophys. Res., 113(C9), C09024 (doi: 10.1029/ 2007JC004656)

Fritsen CH, Ackley SF, Kremer JN and Sullivan CW (1998) Floodfreeze cycles and microalgal dynamics in Antarctic pack ice. In Lizotte MP and Arrigo KR eds. Antarctic sea ice: biological processes, interactions and variability. (Antarctic Research Series 73) American Geophysical Union, Washington, DC, 1-21

Fritsen $\mathrm{CH}$, Wirthlin ED, Momberg DK, Lewis MJ and Ackley SF (2011) Bio-optical properties of Antarctic pack ice in the early austral spring. Deep-Sea Res. II, 58(9-10), 1052-1061 (doi: 10.1016/j.dsr2.2010.10.028)

Galindo V and 9 others (2014) Biological and physical processes influencing sea ice, under-ice algae, and dimethylsulfoniopropionate during spring in the Canadian Arctic Archipelago. J. Geophys. Res., 119(6), 3746-3766 (doi: 10.1002/ 2013JC009497)

Garrison DL and Buck KR (1986) Organism losses during ice melting: a serious bias in sea ice community studies. Polar Biol., 6(4), 237-239 (doi: 10.1007/BF00443401)

Grenfell TC (1991) A radiative transfer model for sea ice with vertical structure variations. J. Geophys. Res., 96(C9), 16991-17001 (doi: 10.1029/91JC01595)

Grenfell TC and Maykut GA (1977) The optical properties of ice and snow in the Arctic Basin. J. Glaciol., 18(80), 445-463

Grossi SM, Kottmeier ST, Moe RL, Taylor GT and Sullivan CW (1987) Sea ice microbial communities. VI. Growth and primary production in bottom ice under graded snow cover. Mar. Ecol. Progr. Ser., 35(1-2), 153-164

Hamre B, Winther J-G, Gerland S, Stamnes JJ and Stamnes K (2004) Modeled and measured optical transmittance of snow-covered first-year sea ice in Kongsfjorden, Svalbard. J. Geophys. Res., 109(C10), C10006 (doi: 10.1029/2003JC001926)

Horner R and Schrader GC (1982) Relative contribution of icealgae, phytoplankton, and benthic micropalgae to primary production in nearshore regions of the Beaufort Sea. Arctic, 35(4), 485-503

Horner R and 9 others (1992) Ecology of sea ice biota. Polar Biol., 12(3-4), 417-427 (doi: 10.1007/BF00243113)

Landy J, Ehn JK, Shields M and Barber DG (2014) Surface and melt pond evolution on landfast first-year sea ice in the Canadian Arctic Archipelago. J. Geophys. Res., 119(5), 3054-3075 (doi: 10.1002/2013JC009617)

Legendre L and Gosselin M (1991) In-situ spectroradiometric estimation of microalgal biomass in first-year sea ice. Polar Biol., 11(2), 113-115 (doi: 10.1007/BF00234273)

Leu E, Søreide JE, Hessen DO, Falk-Petersen S and Berge J (2011) Consequences of changing sea-ice cover for primary and secondary producers in the European Arctic shelf seas: timing, 
quantity, and quality. Progr. Oceanogr., 90(1-4), 18-32 (doi: 10.1016/j.pocean.2011.02.004)

Light B, Grenfell TC and Perovich DK (2008) Transmission and absorption of solar radiation by Arctic sea ice during the melt season. J. Geophys. Res., 113(C3), C03023 (doi: 10.1029/ 2006JC003977)

Markus T, Stroeve JC and Miller J (2009) Recent changes in Arctic sea ice melt onset, freezeup, and melt season length. J. Geophys. Res., 114(C12), C12024 (doi: 10.1029/ 2009JC005436)

Maykut GA and Grenfell TC (1975) The spectral distribution of light beneath first-year sea ice in the Arctic Ocean. Limnol. Oceanogr., 20(4), 554-563

Müller H-G, Wu S, Diamantidis AD, Papadopoulos NT and Carey JR (2009) Reproduction is adapted to survival characteristics across geographically isolated medfly populations. Proc. $R$. Soc. Lond., Ser. B, 276(1677), 4409-4416 (doi: 10.1098/ rspb.2009.1461)

Mundy CJ, Barber DG and Michel C (2005) Variability of snow and ice thermal, physical and optical properties pertinent to sea ice algae biomass during spring. J. Mar. Syst., 58(3-4), 107-120 (doi: 10.1016/j.jmarsys.2005.07.003)

Mundy CJ, Ehn JK, Barber DG and Michel C (2007) Influence of snow cover and algae on the spectral dependence of transmitted irradiance through Arctic landfast first-year sea ice. J. Geophys. Res., 112(C3), C03007 (doi: 10.1029/2006JC003683)

Nicolaus M and Katlein C (2013) Mapping radiation transfer through sea ice using a remotely operated vehicle (ROV). Cryosphere, 7(3), 763-777 (doi: 10.5194/tc-7-763-2013)

Nicolaus M, Katlein C, Maslanik J and Hendricks S (2012) Changes in Arctic sea ice result in increasing light transmittance and absorption. Geophys. Res. Lett., 39(24), L24501

Palmisano AC, Beeler SooHoo J and Sullivan CW (1987) Effects of four environmental variables on photosynthesis-irradiance relationships in Antarctic sea-ice microalgae. Mar. Biol., 94(2), 299-306 (doi: 10.1007/BF00392944)

Perovich DK (1990) Theoretical estimates of light reflection and transmission by spatially complex and temporally varying sea ice covers. J. Geophys. Res., 95(C6), 9557-9567 (doi: 10.1029/ JC095iC06p09557)

Perovich DK (2005) On the aggregate-scale partitioning of solar radiation in Arctic Sea Ice during the SHEBA field experiment. J. Geophys. Res., 110(C3), C03002 (doi: 10.1029/ 2004JC002512)

Perovich DK, Cota GF, Maykut GA and Grenfell TC (1993) Biooptical observations of first-year Arctic sea ice. Geophys. Res. Lett., 20(11), 1059-1062 (doi: 10.1029/93GL01316)

Perovich DK, Roesler CS and Pegau WS (1998) Variability in Arctic sea ice optical properties. J. Geophys. Res., 103(C1), 1193-1208 (doi: 10.1029/97JC01614)

R Core Team (2013) R: a language and environment for statistical computing. R Foundation for Statistical Computing, Vienna http://www.r-project.org

Ramsay JO (2006) Functional data analysis. In Kotz S, Read CB and Banks DL eds. Encyclopedia of statistical sciences. Wiley (doi: 10.1002/0471667196.ess3138)

Ramsay JO and Silverman BW (2005) Functional data analysis, 2nd edn. Springer, New York

Ramsay JO, Hooker G and Graves S (2009) Functional data analysis with $R$ and MATLAB (use R!). Springer, Dordrecht

Ramsay J, Wickham H, Graves S and Hooker G. (2012) fda: Functional data analysis, $R$ package. Version 2.3.2. http://cran. r-project.org/web/packages/fda/

Smith REH, Anning J, Clément P and Cota GF (1988) The abundance and production of ice algae in Resolute Passage, Canadian Arctic. Mar. Ecol. Progr. Ser., 48, 251-263

Sørensen H, Goldsmith J and Sangalli LM (2013) An introduction with medical applications to functional data analysis. Stat. Med., 32(30), 5222-5240 (doi: 10.1002/sim.5989)

Stroeve JC and 6 others (2012) Trends in Arctic sea ice extent from CMIP5, CMIP3 and observations. Geophys. Res. Lett., 39(16), L16502 (doi: 10.1029/2012GL052676)

Vines BW, Krumhansl CL, Wanderley MM and Levitin DJ (2006) Cross-modal interactions in the perception of musical performance. Cognition, 101, 80-113 (doi: 10.1016/j.cognition. 2005.9.003) 